SANDPS- $2374 C$

\title{
COMPACTION OF SPRAY-DRIED CERAMIC POWDERS: AN EXPERIMENTAL STUDY OF THE FACTORS THAT CONTROL GREEN DENSITY
}

\author{
Michael J. Readey and F. Michael Mahoney \\ Glass and Electronic Ceramics \\ Sandia National Laboratories \\ Albuquerque, NM 87185-0333
}

\begin{abstract}
The pressure-compaction response of a spray-dried, $94 \%$ alumina powder containing several percent of a polymeric binder was investigated as a function of die diameter and compact aspect ratio. The results show that the die fill density decreases markedly with decreasing die diameter and aspect ratio, while the final green density (at $120 \mathrm{MPa}$ ) decreases only slightly under the same conditions. These results suggest that the ratio of the initial compact dimensions to the size of the granules may be much more important than previously considered.
\end{abstract}

KEY WORDS: Compaction, green density, density variations.

\section{INTRODUCTION}

Compaction of spray-dried ceramic powders by die-pressing currently is the predominant forming technique used in fabricating advanced ceramics for technical applications. Moreover, due to its ability to form complex shapes in high volume, die-pressing will continue to be used more than any other technique into the foreseeable future. However, one significant disadvantage of die-pressing is that it leads to variations in compact density throughout the component due to the influence of powder-die wall friction. These variations ultimately result in shrinkage variability later in the sintering process, often requiring costly diamond grinding in order to obtain the desired component dimensions. Thus, understanding the mechanics of compaction and the variables that control green density are of vital importance to industry.

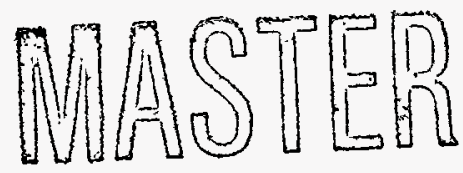


Compaction is generally considered to consist of three primary stages, as schematically illustrated in Figure 1. First, the granulated powder is poured into the die cavity; the density at this stage is known as the die fill density, and is determined primarily by the properties of the spray-dried granules. It should be noted that almost all pressing of ceramic powders involves a preliminary spray-drying operation. Most ceramic powders for technical ceramics are extremely fine $(\sim 1$ micron) and do not flow well. Thus, granulating the powders by forming a slurry of the powder and a liquid (usually water), followed by spray-atomization in a heated drying chamber creates more flowable granules on the order of 100 microns in size, as shown in Figure 2. Additionally, a soluble, polymeric binder is added to the slurry to bond the individual powder particles in the granule, and to give the resulting pressed powder compact sufficient strength to withstand subsequent handling. During the second stage of the compaction process (see Figure 1), the top punch compresses the powder under pressure to the desired green density, where the term "green" refers to the as-pressed (unfired) condition. Finally, the pressure is removed and the bottom punch ejects the part from the die.

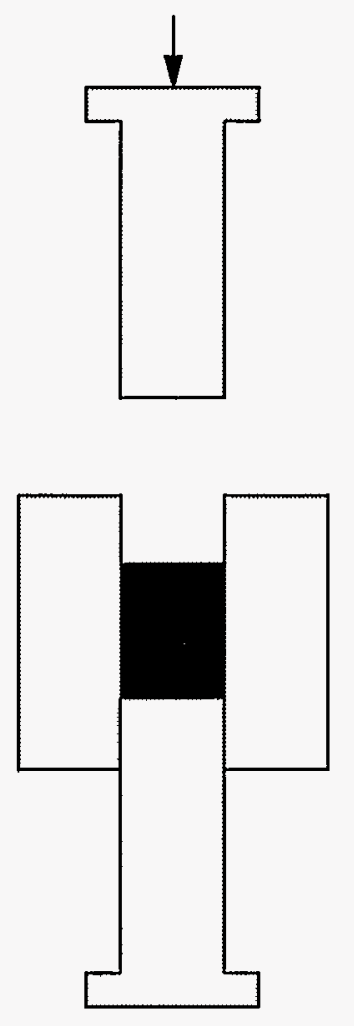

(1)

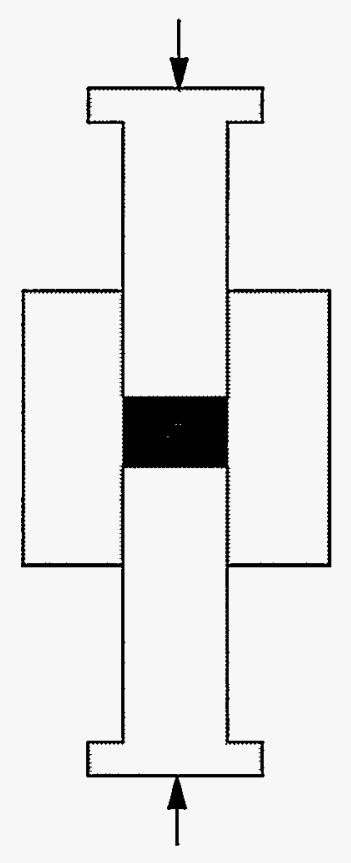

(2)

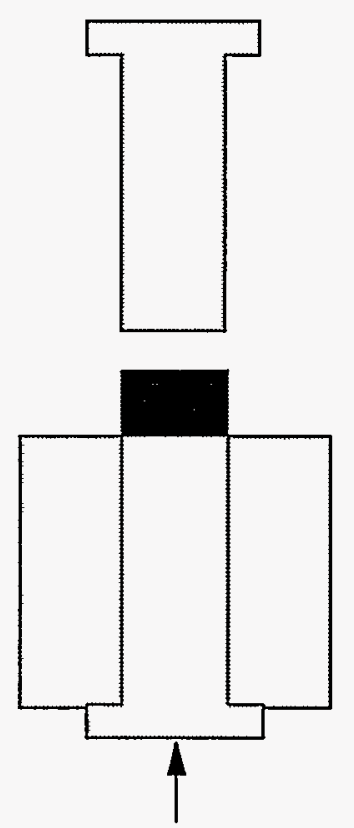

(3)

Figure 1. The basic stages of compaction: (1) powder fills the die cavity, known as die fill; (2) the punches compact the powder under pressure; (3) pressure is released and the compact is ejected from the die. 


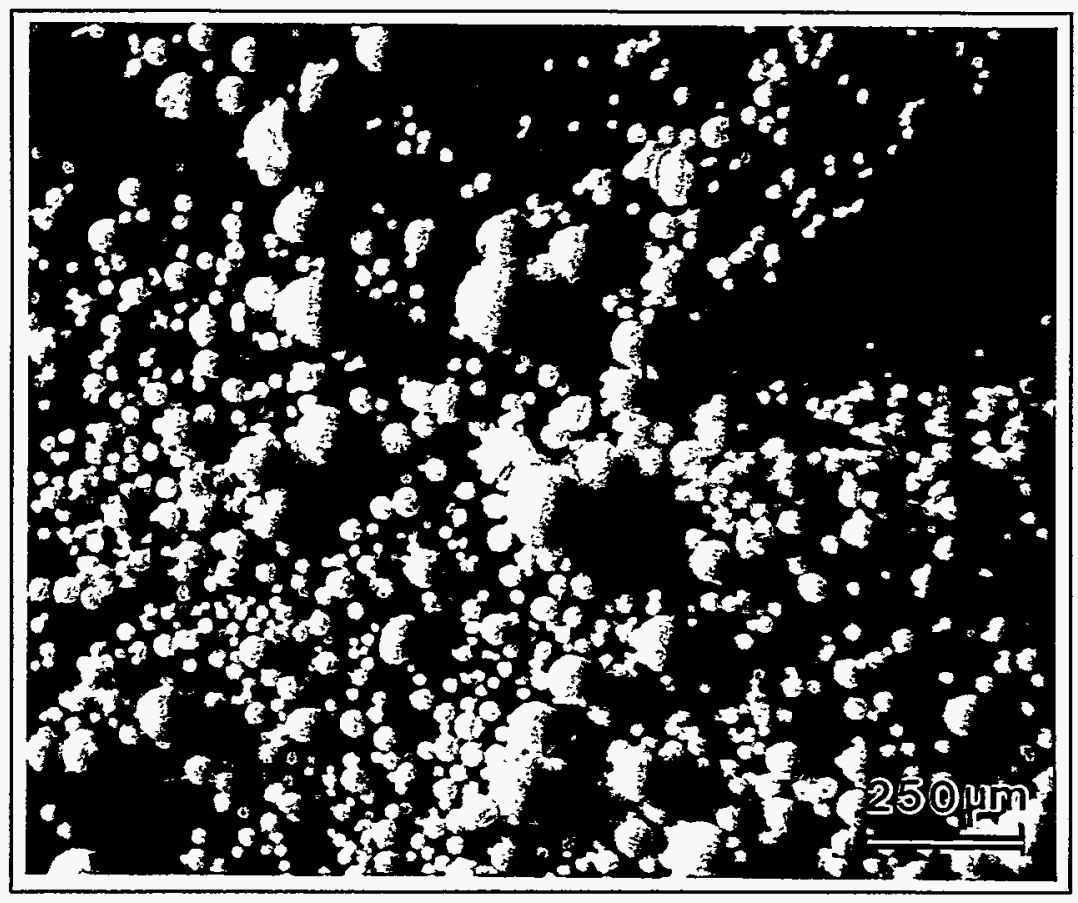

Figure 2. Optical micrograph of spray-dried granules. They are typically spherical, with a broad particle size distribution and an average diameter on the order of 100 microns. Note that each granule is composed of primarily alumina particles 1 micron is diameter, lightly bonded together with a polymeric binder.

The compaction process has received a great deal of attention during the past several decades by investigators from the ceramics community. Compaction has also been studied extensively by the powder metallurgy community, as well as the pharmaceutical community. As such, a great deal has been learned concerning the mechanics of the compaction process. For example, Unkel (1), Kuczynksi and Zaplatynskyj (2), and later Train and Lewis (3) showed experimentally that significant density gradients exist in powder compacts. Such behavior was predicted nearly fifty years earlier by Janssen (4), who suggested that pressure gradients will exist in granular compacts due to the influence of die-wall friction restricting granule movement in the near die wall region. Subsequently several investigators have attempted to develop analytical models that describe the experimental observations. Some of these models are reviewed in our companion paper (Reference 5, this volume).

Several investigators have focused on the pressure-compaction response of spray-dried ceramic powders. Cooper and Eaton (6) were some of the first to propose a physical description of the compaction process by modeling the pore volume as a function of applied pressure. Reed and co-workers (7-9) have provided a great deal of information on compaction, focusing their attention on both material effects as well as the mechanics of stress transmission. Halloran et al. $(10,11)$ have also examined die-pressing, noting the significant influence of the binder on the resulting density of the compact. 
In spite of the volumes of work on compaction of powders, few studies have focused on the effect of die diameter and aspect ratio on the compaction process. For instance, Bocchini (12) has suggested that the die diameter becomes increasingly important as the die diameter decreases, due to less efficient granule packing. This is also supported by recent modeling efforts by Cesarano et al. (13). In this study, we explore the influence of die diameter and aspect ratio on the initial fill density, pressure-compaction response, and final pressed density of a typical spray-dried $94 \%$ alumina powder (e.g., the powder shown in Figure 2). We have focused our attention on pressures typically found in industry, and with die sizes commonly found in many die-pressed components in order to better understand compaction of actual components.

\section{EXPERIMENTAL PROCEDURE}

A spray-dried, $94 \%$ alumina powder ${ }^{1}$ containing several percent of a methylcellulose binder was used throughout this study. Cylindrical dies were used due to their simplicity in operation, and because any density variability would presumably be symmetric about the central axis. Four different die diameters were chosen: $25 \mathrm{~mm}(1 "), 12.5 \mathrm{~mm}\left(1 / 2^{\prime \prime}\right), 6.2 \mathrm{~mm}$ $\left(1 / 4^{\prime \prime}\right)$, and $3.1 \mathrm{~mm}\left(1 / 8^{\prime \prime}\right)$. All of the dies were machined such that the punch-die cavity tolerances were identical. Moreover, the die cavities were ground under identical conditions, and the surface roughness measured to ensure that the die wall friction was approximately uniform. The dies were also modified to accept a displacement gauge. Three aspect ratios (compact thickness-to-die diameter) were chosen, reflecting a wide range of typical operating conditions: $0.75,0.38$, and 0.08 . In this study, a completely randomized, full factorial matrix was designed using three replicates per combination of variables, resulting in a total of 36 experiments.

Experiments were performed by first setting the height of the punch to achieve the desired aspect ratio. (Preliminary experiments revealed a compaction ratio (initial-to-final thickness) of approximately 2 . Thus the punches were set to initial aspect ratios of 1.5 , 0.75 , and 0.15 . Powder was poured into the die until it overflowed somewhat; the excess removed by passing a knife-edge over the die cavity. Note that this type of die fill results in compacts of slightly different mass (for the same conditions), but is more typical of industrial die-filling operations. At this point, the bottom punch was retracted slightly and the top punch inserted. The entire assembly was then placed in an MTS servohydraulic universal testing machine fitted with a high resolution load cell. A high-resolution extensometer was attached to the die as shown in Figure 3.

The test was initiated by moving the servohydraulic ram on the testing machine upwards at a rate of $3 \mathrm{~mm} / \mathrm{min}$ until an applied pressure of $140 \mathrm{MPa}$ was achieved $(\sim 20 \mathrm{ksi})$. Compaction pressures were monitored by the load cell, and displacement of the punches measured with the extensometer. These data were collected using an on-line data acquisition system at rates sufficient to provide approximately one hundred data points per test. Corrections for the load train and die compliance were also made according the method of Glass (14). Once completed, the compacts were ejected from the die, and their mass and dimensions measured. Densities were then calculated based on the mass and

1 Note that the $94 \%$ alumina implies $94 \%$ (by weight) of pure alumina, with $6 \%$ of $\mathrm{CaCO}_{3}, \mathrm{MgCO}_{3}$, and $\mathrm{SiO}_{2}$ added as sintering aids. 


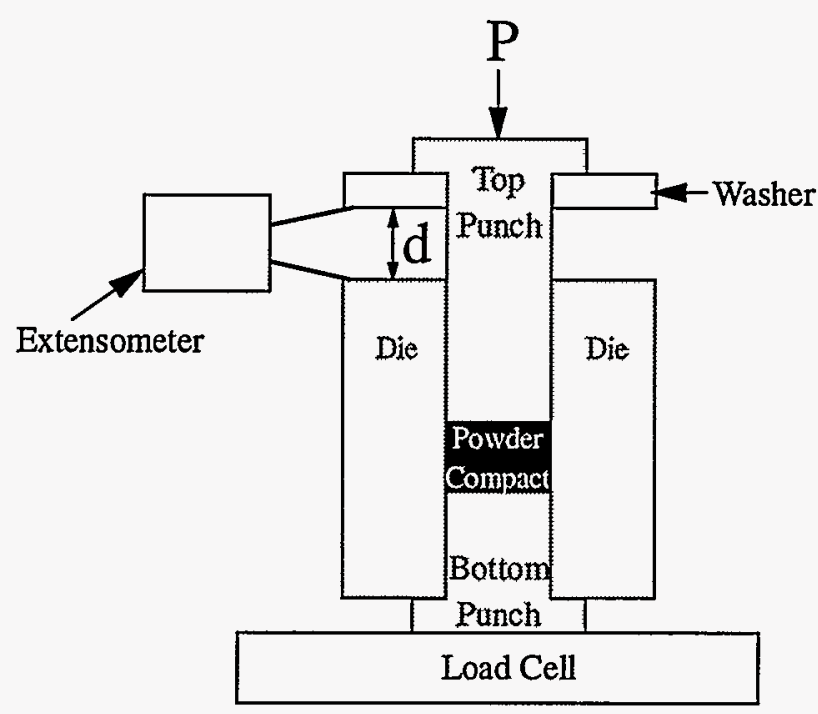

Figure 3. Experimental setup for compaction of spray-dried $94 \%$ alumina, measuring displacement, $\mathrm{d}$, and compaction load, $\mathrm{P}$, simultaneously.

volume of the compact at any point in the test by noting that the compact diameter was the die diameter, and that the compact thickness was:

$$
t_{t}=\left(t_{f}+d_{t o t}\right)-d_{t}
$$

where $t_{t}$ is the thickness at time $t, t_{\mathrm{f}}$ is the final thickness, $d_{\text {tot }}$ is the total punch displacement,

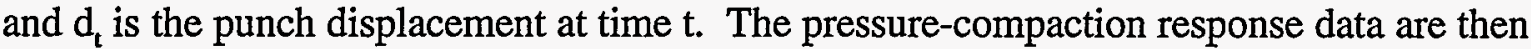
plotted as a function of relative density versus applied pressure in both linear coordinates, and the more customary semilogarithmic coordinates (15). The initial die fill density was assumed to be the first data set in the file, and the compacted green density the computed green density at $120 \mathrm{MPa}$.

\section{RESULTS}

\subsection{Test Reproducibility}

Figure 4 shows the relative density as a function of applied pressure for the three trials using a $25 \mathrm{~mm}$ die diameter and a final aspect ratio of 0.75 . Results are similar for other combinations of die and aspect ratio. The pressure compaction curves are nearly identical for all three runs, indicating excellent reproducibility throughout the test matrix. Initial and final densities (at $120 \mathrm{MPa}$ varied by approximately 1 and $0.5 \%$, respectively.

The general compaction response can be described as a rapid increase in density during the initial stages of compaction (up to $\sim 20 \mathrm{MPa}$ ), followed by a decrease in the densification rate with further increases in applied pressure (Figure 4a). Plotting the same data as a function of the logarithm of applied pressure reveals a nearly constant densification behavior at the onset of the compaction process, followed by a rapid increase in density, with a slightly lower densification rate at higher pressures. Traditionally, these regions are believed to correspond to: (1) granule rearrangement at low pressures; (2) granule deformation and fracture; (3) individual particle rearrangement and fracture at high pressures. 


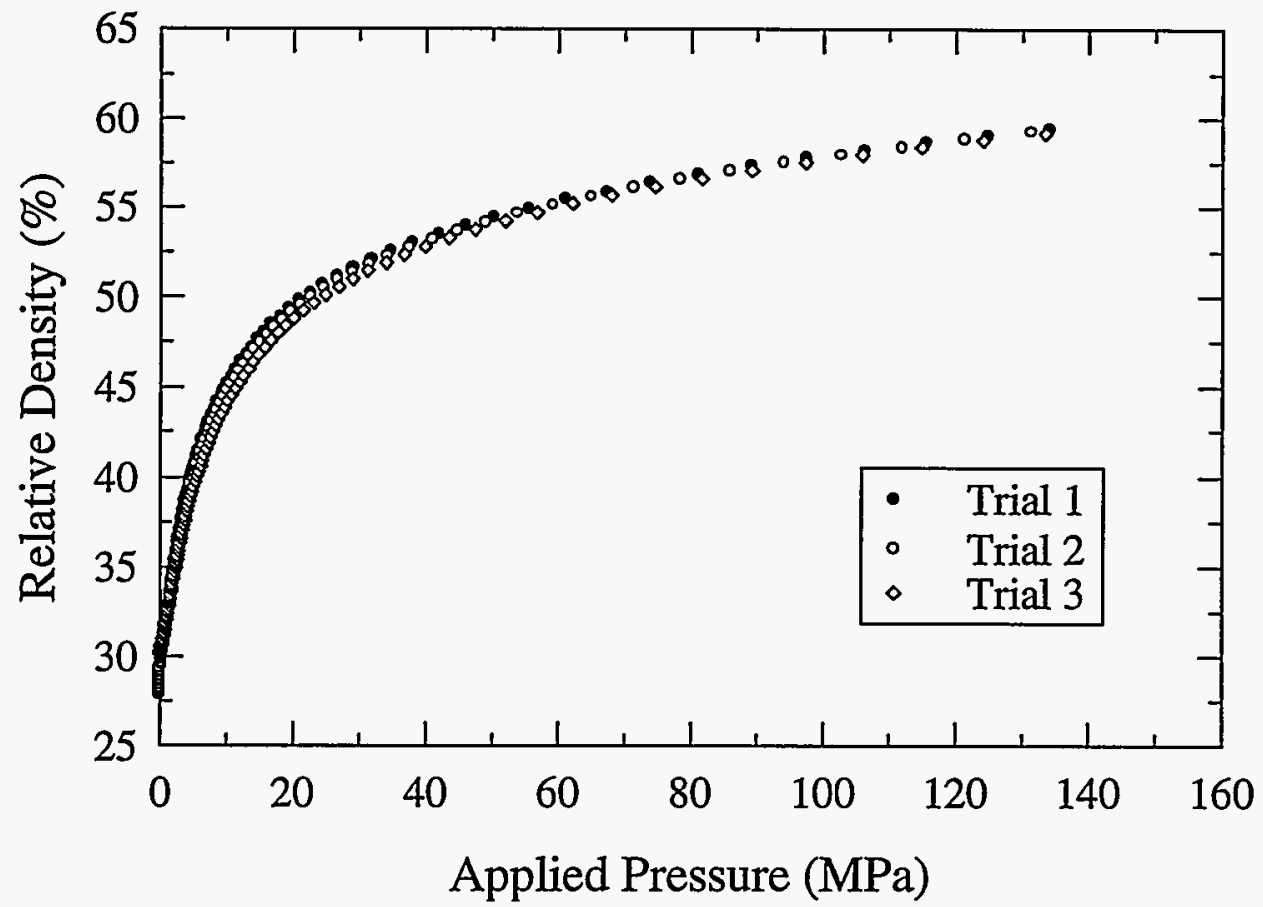

(a)

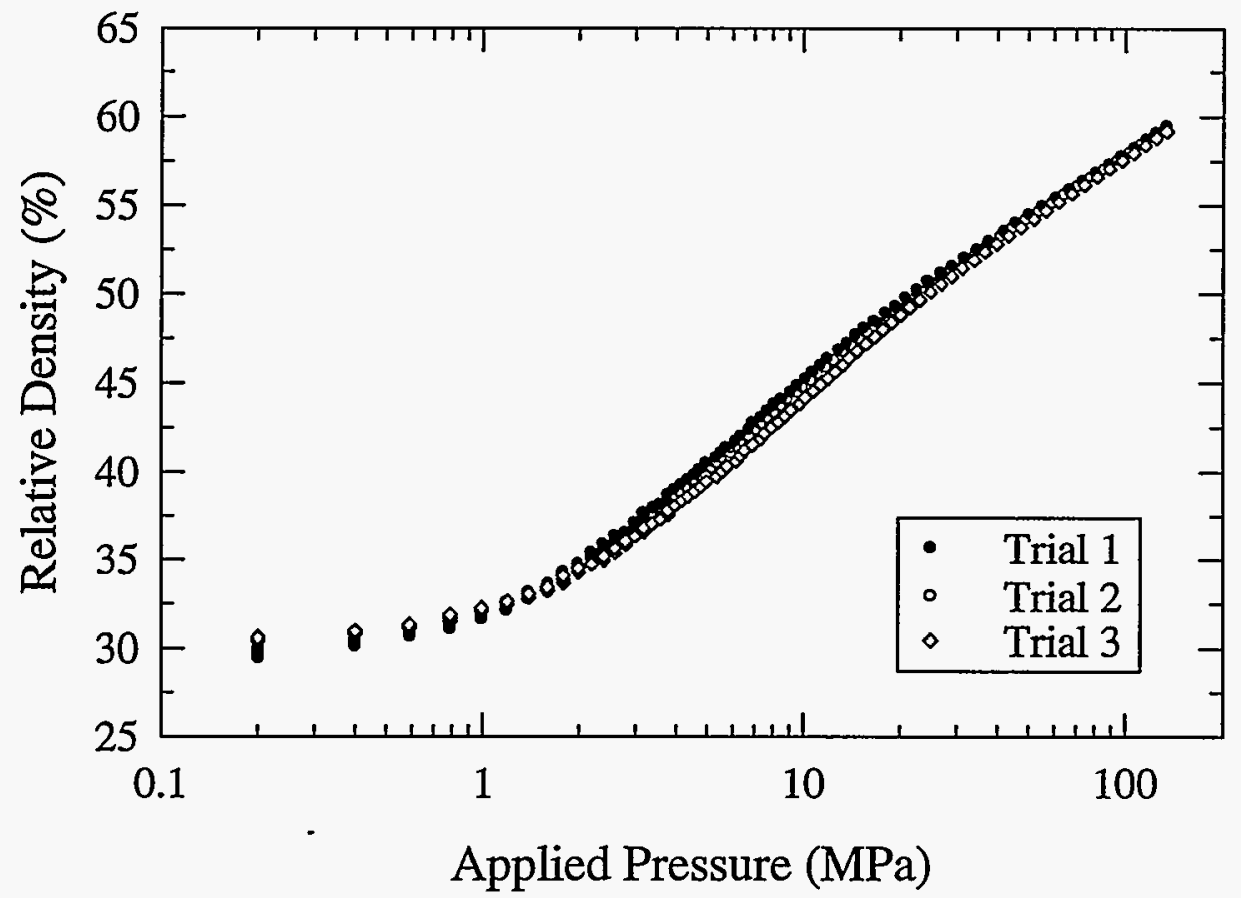

(b)

Figure 4. Relative density versus applied pressure for the $25 \mathrm{~mm}$ (1") die with a final aspect ratio of 0.75 ; (a) linear, and (b) semilogarithmic coordinates. Note that all three trials give nearly identical results. 


\subsection{Pressure Compaction Response as a Function of Die Diameter}

Figure 5 shows the typical compaction response of the alumina powder as a function of die diameter for compacts having a final aspect ratio of 0.75 . The general trend is that the smaller die diameters tend to lead to lower the initial and final densities. The exception is the smallest $(3 \mathrm{~mm})$ die, which shows more complex behavior. It is not clear at present why these data are so different; there is considerably more scatter in the $3 \mathrm{~mm}$ data, suggesting that deviation from the general trend may in part be due to statistical errors in measurement.

\subsection{Pressure Compaction Response as a Function of Aspect Ratio}

Figure 6 shows representative compaction responses of the alumina powder as a function of aspect ratio, using the $12.5 \mathrm{~mm}\left(1 / 2^{\prime \prime}\right)$ die. Again, the responses are similar, with the 0.75 and 0.38 data nearly identical. The lowest aspect ratio response is displaced to lower densities; the densification rate at higher pressures is also slightly less than the higher two aspect ratios (Figure 6b).

\subsection{Effect of Die Diameter and Aspect Ratio on Fill Density}

The influence of die diameter and aspect ratio on fill density is shown in Figure 7. For the $25 \mathrm{~mm}$ die, the fill density is nearly constant at approximately $28 \%$ of theoretical density. However, smaller die diameters show a much larger effect on fill density. Specifically, the fill density decreases rapidly with decreasing die diameter, to nearly $21 \%$ for the $6.2 \mathrm{~mm}$ die. (The specimens pressed with the $3 \mathrm{~mm}$ die were too fragile to obtain density data on the 0.08 aspect ratio.) Moreover, the magnitude of the difference is also a strong function of aspect ratio; the greatest differences in fill density occurred at the lowest aspect ratio.

\subsection{Effect of Die Diameter and Aspect Ratio on Final Compacted Density}

Figure 8 shows the influence of die diameter and aspect ratio on the final compacted density for compaction pressures of $120 \mathrm{MPa}$. The data show the same strong trends as indicated for the fill density, namely that in general the lowest compacted densities occur with the smallest die diameter and the lowest aspect ratio. In fact, the density drops by as much as $10 \%$ of theoretical between the $25.5 \mathrm{~mm}$ die and the $6.25 \mathrm{~mm}$ die for the lowest aspect ratio of 0.08 . 


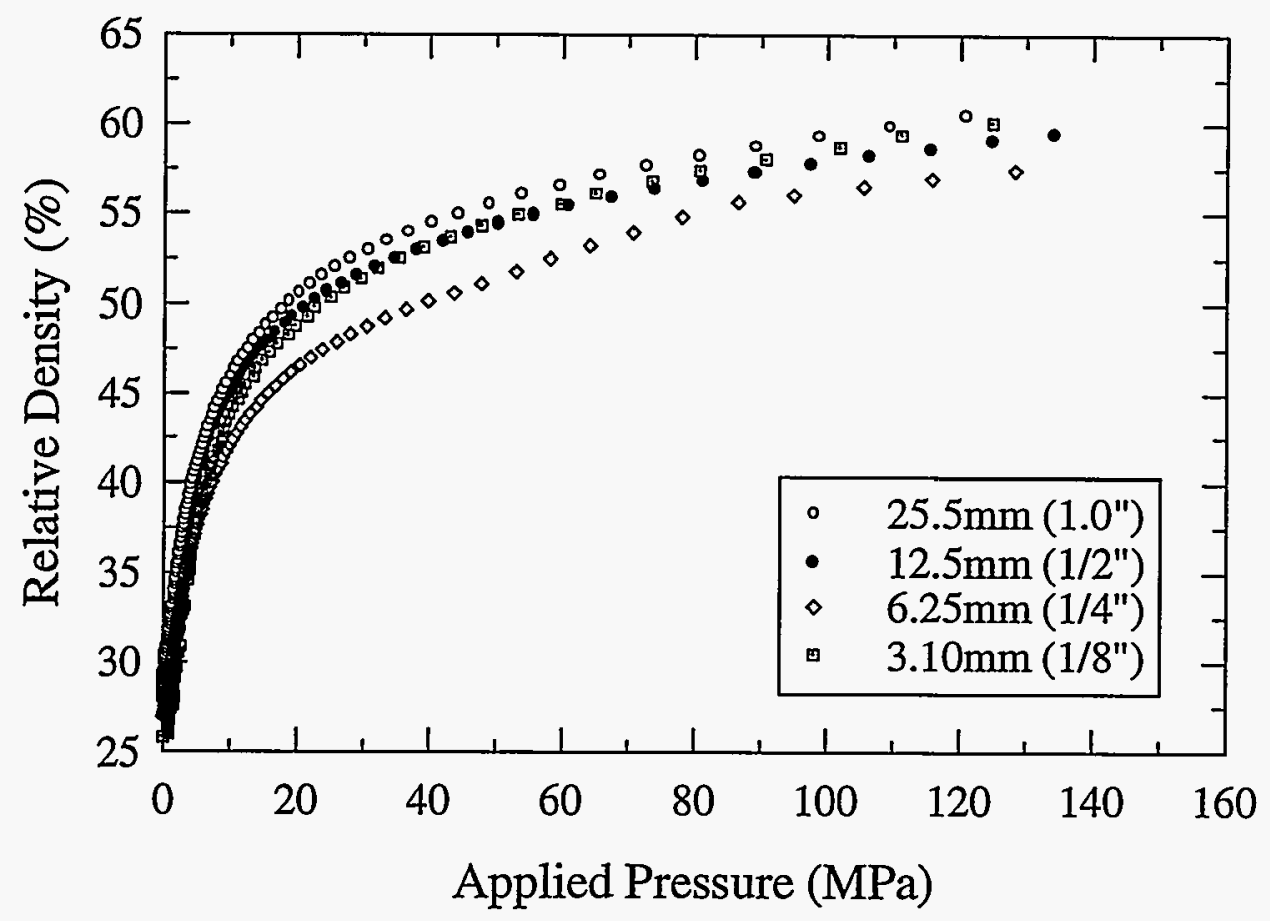

(a)

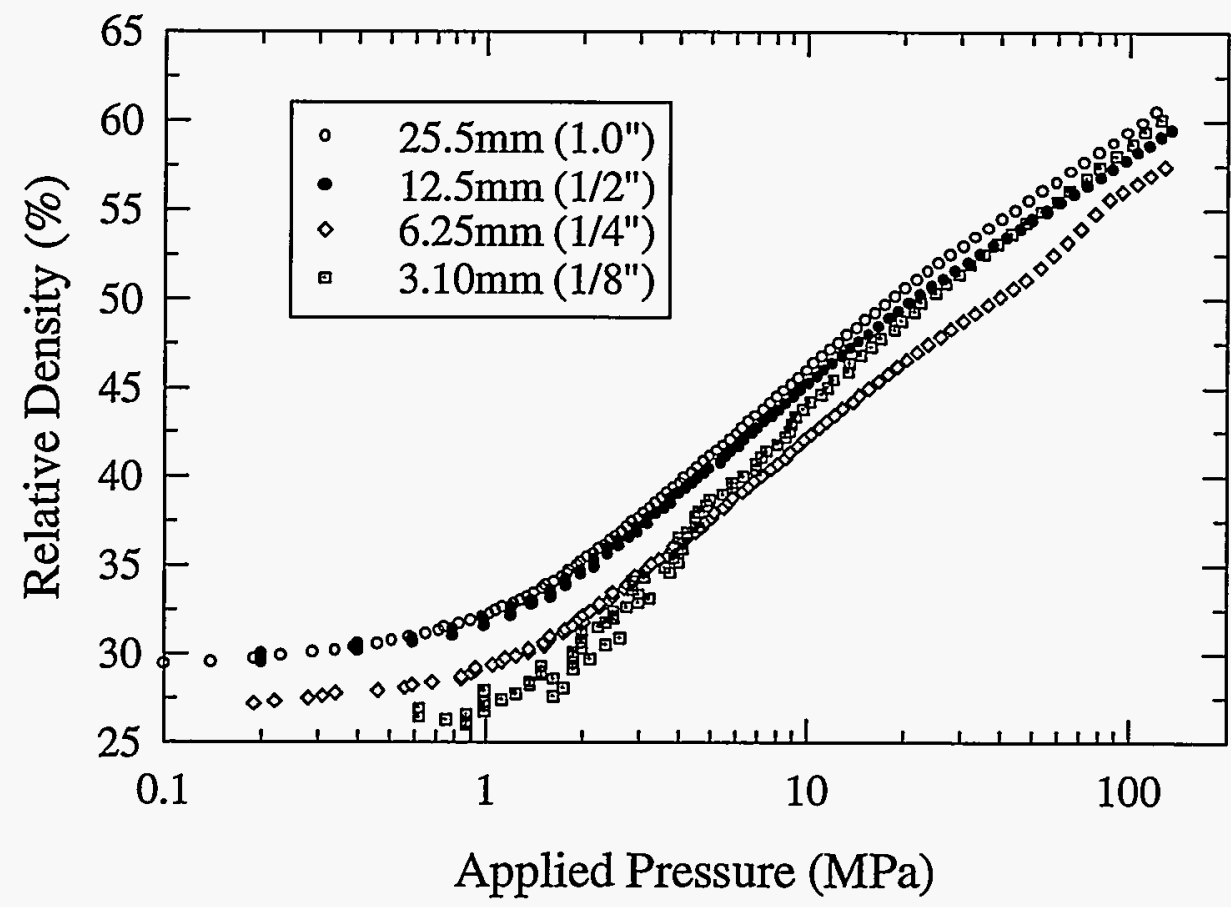

(b)

Figure 5. Relative density versus applied pressure for $94 \%$ alumina powder as a function of die diameter, with a constant final aspect ratio of 0.75 ; (a) linear and (b) semilogarithmic coordinates. The responses are generally similar, although the $3 \mathrm{~mm}$ die (1/8") shows different behavior, beginning at a lower fill density and achieving a very high density. 


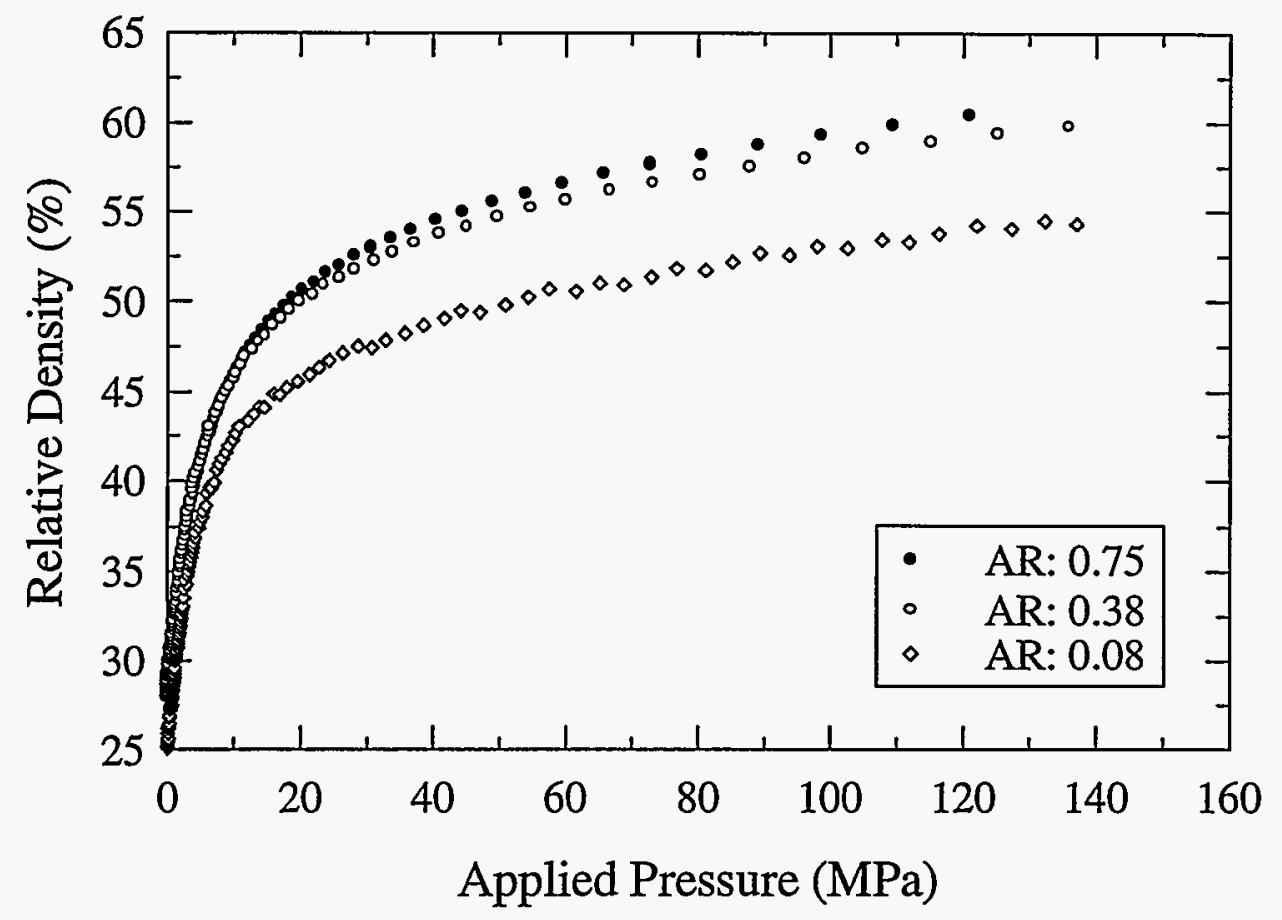

(a)

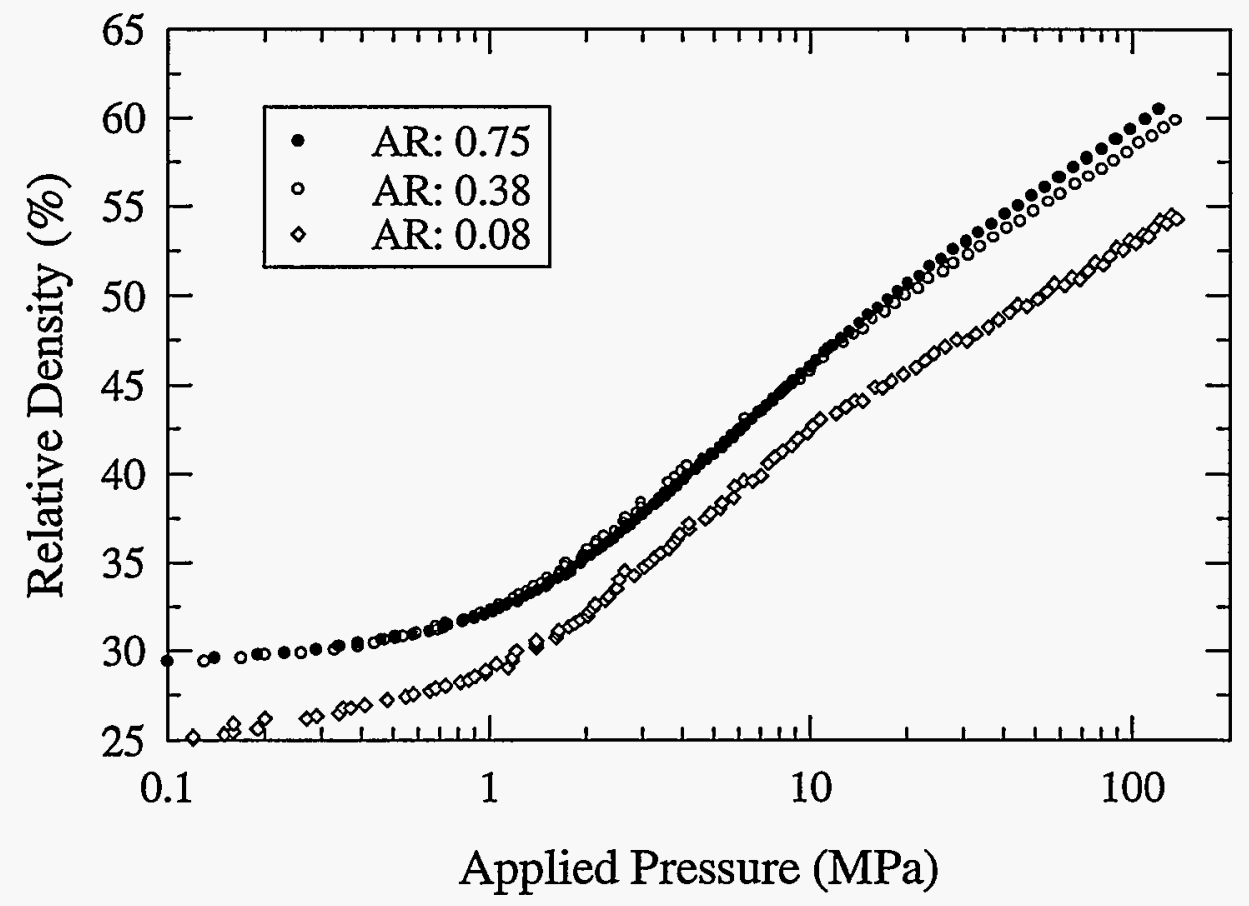

(b)

Figure 6. Relative density versus applied pressure for $94 \%$ alumina powder compacted in a $12.5 \mathrm{~mm}(1 / 2$ ) die as a function of aspect ratio; (a) linear, and (b) semilogarithmic coordinates. The compaction responses are similar, but displaced to lower densities with decreasing aspect ratio. 


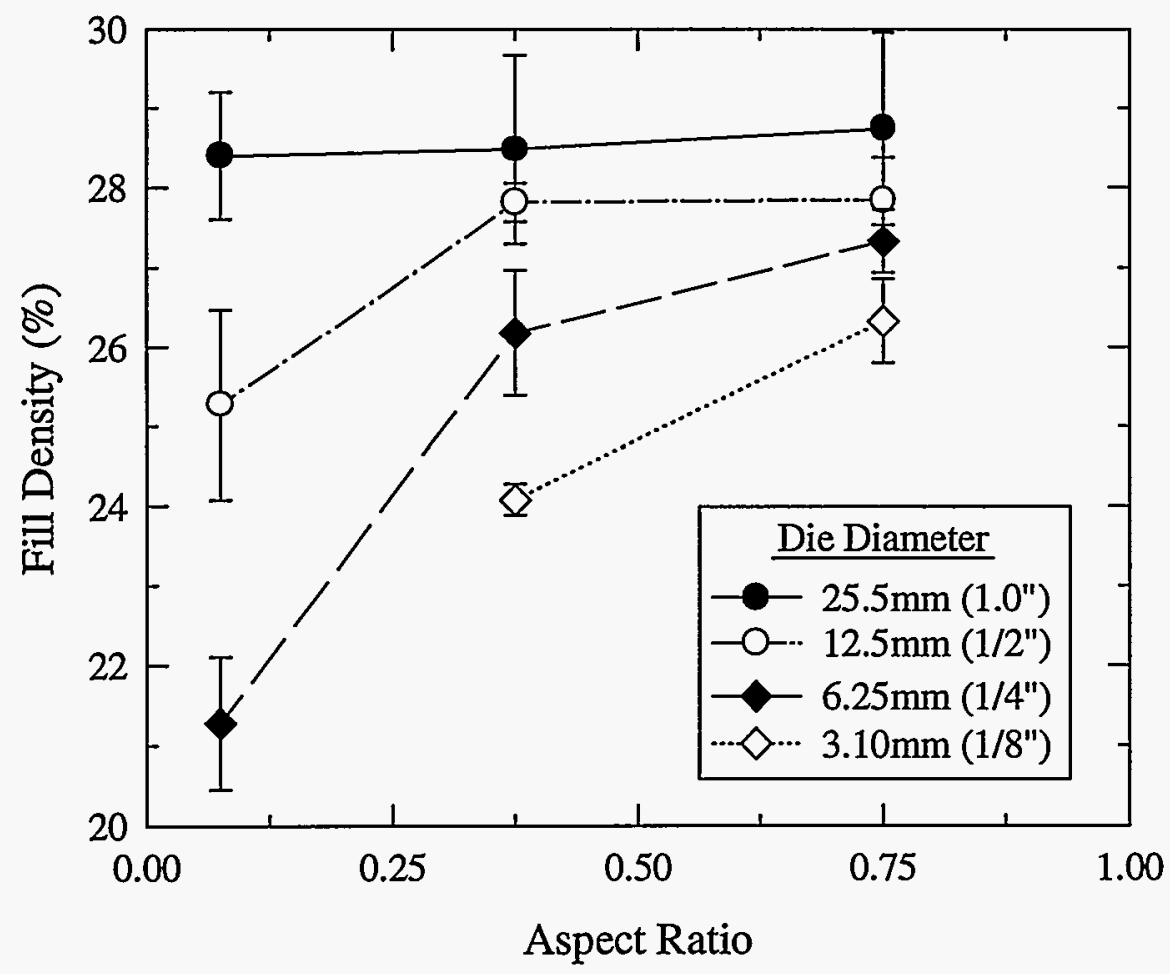

Figure 7. Initial fill density versus aspect ratio for $94 \%$ alumina powder as a function of die diameter. Note that the fill density is a strong function of both die diameter and aspect ratio.

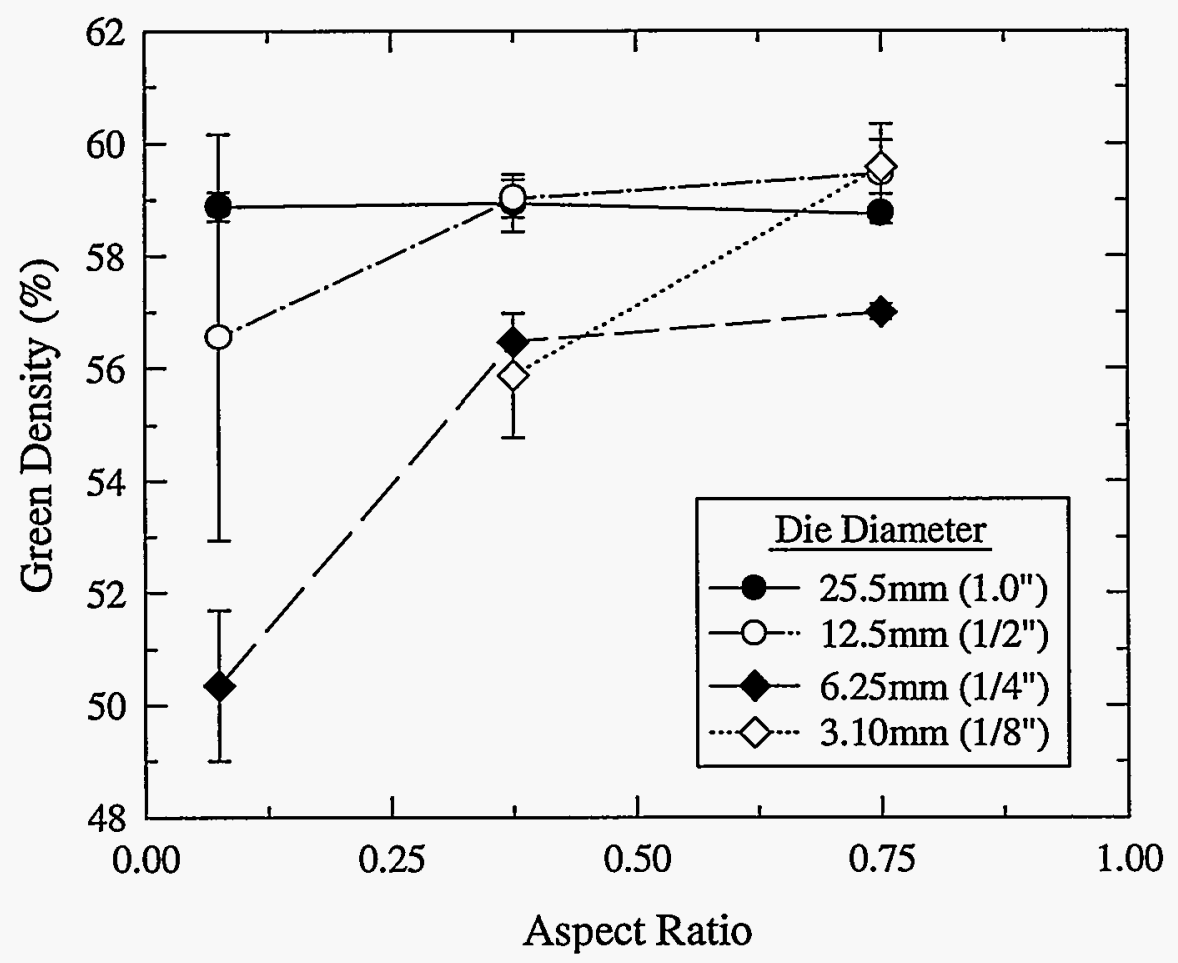

Figure 8. Relative density versus aspect ratio for $94 \%$ alumina powder compacted to $120 \mathrm{MPa}$ as a function of die diameter. In general, the density is lower for smaller dies and lower aspect ratios. 


\section{DISCUSSION}

The pressure-compaction response of a spray-dried alumina powder containing a small amount of a polymeric binder phase was examined. In general, the overall density versus applied pressure curves were similar in nature; all had three distinct regions of an initially small increase in density up to a few MPa is pressure, followed by a rapid increase up to approximately $20 \mathrm{MPa}$, again followed by a more slowly increasing density as the pressure was increased to the maximum of about $140 \mathrm{MPa}$. This suggests that there are no significant changes in compaction mechanism with die diameter or aspect ratio.

However, both the die diameter and aspect ratio exhibited a significant influence on the initial fill density and final compacted density at 120MPa. In both of these cases, the densities decreased as either the die diameter or aspect ratio decreased. To explore whether lower fill densities always led to lower compacted densities, regardless of die or aspect ratio, the data are simply plotted against each other. The result is shown in Figure 9, and suggests that there is a strong correlation between initial and final compact densities.

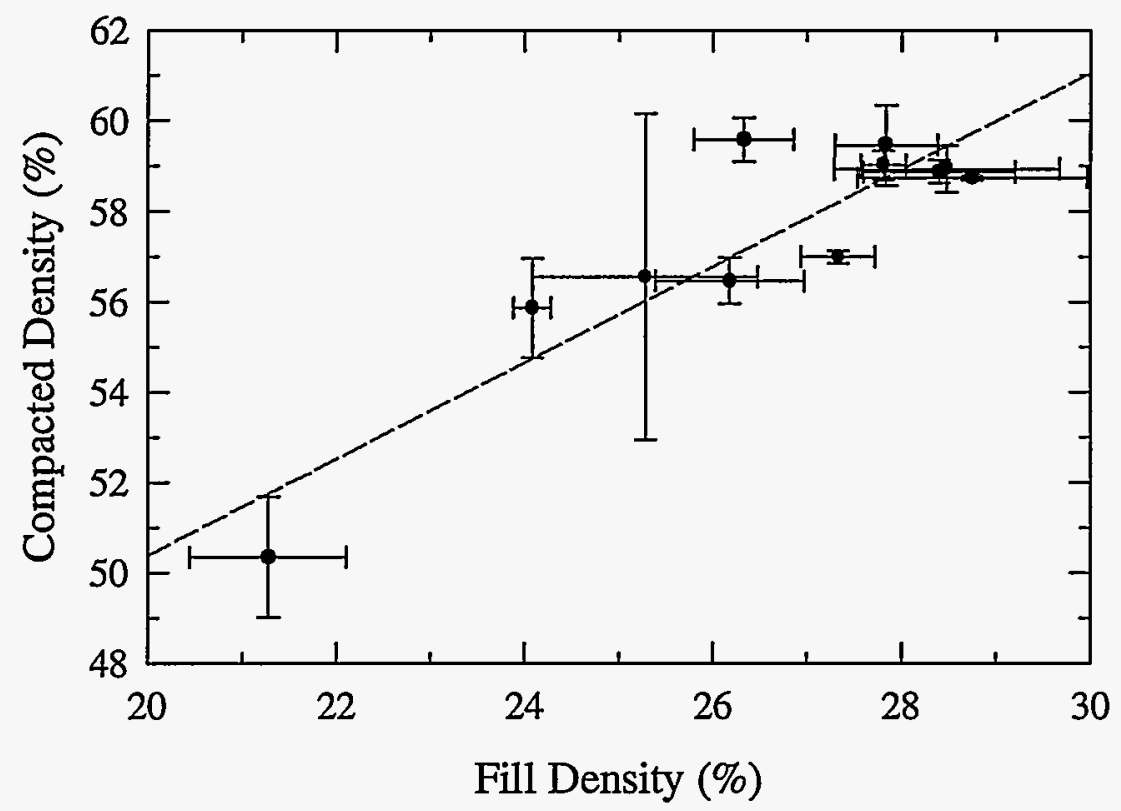

Figure 9. Compacted density at applied pressure of $120 \mathrm{MPa}$ versus initial fill density. Note that within the scatter of the data, the compacted density clearly increases with increasing fill density.

This suggests that the packing efficiency of the granules is directly related to the die diameter and aspect ratio, and that the final compaction efficiency is linked directly to the granule packing efficiency. The role of die diameter on packing efficiency was previously investigated by Bocchini (12), who postulated that as the granule diameter becomes a sizable fraction of the die diameter, then the packing density (e.g., the fill density) will decrease due to the influence of the die wall, an effect also shown in packing simulations by Cesarano (13). This concept is schematically illustrated in Figure 10 for two sized granules and the same size die. Note that when the granules are small relative to the die, the wall has little influence on packing efficiency. However as the granules become large relative to the die, the influence of the die wall is important. 


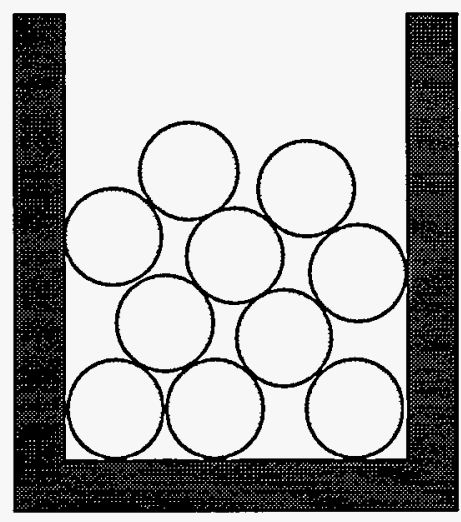

(a)

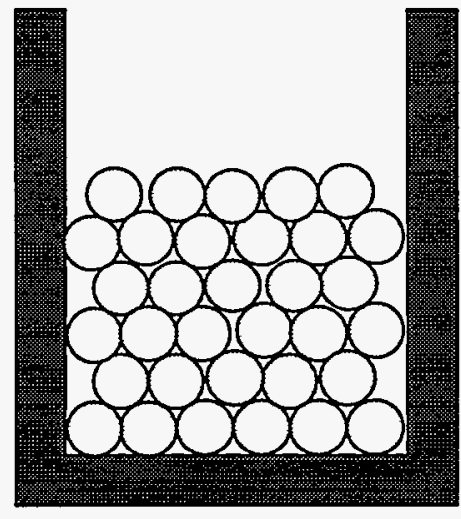

(b)

Figure 10. Effect of granule-die diameter ratio on packing efficiency of uniform spheres. Note that when the granule size becomes large relative to the die diameter (a), the packing efficiency decreases. Packing efficiency increases with a smaller granule-die diameter ratio. Experimentally, the packing efficiency is equivalent to the fill density.

While Figure 10 clearly exaggerates the effect of die diameter on packing efficiency, the compaction data suggest that the influence of the die diameter becomes relatively unimportant when the granule size is $\sim 0.001$ the size of the die diameter (as observed with the $25 \mathrm{~mm}$ die). Such a value has also obtained by modeling studies of Cesarano et al. (13). The significance of this result is that one should tailor the size distribution of the spray-dried granules to the dimensions of the die used during compaction to obtain the maximum fill density. While industry typically fractionates spray-dried granules into usable size ranges, it generally does not adjust the size ratio to the die diameter.

The influence of die diameter on fill density can be readily described by the above physical model. However, the effect of aspect ratio is less clear. Results show that the fill density (and consequently the final compacted density) decrease with decreasing aspect ratio. This is surprising, as it is generally believed that the greater the contact area of the die wall with the powder, the more significant the frictional forces. Thus decreasing the aspect ratio minimizes the powder-die wall area, and would thus minimize die wall frictional effects on the die fill operation. Clearly, this model strains credulity in light of the results of this study. Other mechanisms heretofore not considered may be operative. For example, the mass of the powder in the die increases as the aspect ratio is increased. Possibly this increase in mass contributes to a packing effect, as considered in Janssen's early models of compaction (4). We are currently investigating this and other mechanisms that could contribute to the observed results.

\section{CONCLUSIONS}

The compaction response of a $94 \%$ alumina powder containing several percent of a polymeric binder was investigated as a function of die diameter and aspect ratio. The testing technique devised was extremely reproducible, allowing for small differences to be observed in the compaction response and identification of the initial fill densities and final compacted densities. The results show that the die and aspect ratio have little influence 
over the general shape of the density-pressure response curve. However, the fill and final compacted density are strong functions of die diameter and aspect ratio. Moreover, final compacted densities are controlled in large part by the initial fill density. A simple model was used to explain the effect of die diameter on fill density. These results suggest further that high fill densities (and consequently high compacted densities) will be obtained by tailoring the granule size distribution such that the granule size is small compared to the die diameter.

\section{Acknowledgements}

The authors would like to thank Clay Newton and Mark Reece for their assistance in conducting the experiments. Many spirited discussions with Jill Glass, Joe Cesarano, and Kevin Ewsuk are also gratefully appreciated. This work was conducted at Sandia National Laboratories, and was supported by the Department of Energy under Contract Number DE-ACO4-94AL85000.

\section{REFERENCES}

1. H. Unkel, Arch. Eisenhuttenw., 18 (1-2) 161 (1945).

2. G.C. Kuczynksi and I. Zaplatatynskyj, J. Metals, $\underline{8}$ (2) 215 (1956).

3. D. Train and C.J. Lewis, Trans. Instn. Chem. Engrs., 4018 (1962).

4. H.A. Janssen, Zeit. d. Vereins Deutsch. Ing., 39 (35) 1045 (1895).

5. F. Michael Mahoney, and Michael J. Readey, this volume.

6. A.R. Cooper and L.E. Eaton, J. Am. Ceram. Soc., 45 (3) 97 (1962).

7. S.J. Lukasiewicz and J.S. Reed, Am. Ceram. Soc. Bull., 57 (9) 798 (1978).

8. R. A. DiMilia and J.S. Reed, Am. Ceram. Soc. Bull., 62 (4) 485 (1983).

9. J. Zheng and J. S. Reed, J. Am. Ceram. Soc., 71 (11) C-456 (1988).

10. F.W. Dynys and J.W. Halloran, J.Am. Ceram. Soc., 66 (9) 655 (1983).

11. R.G. Frey and J.W. Halloran, J. Am. Ceram. Soc., 67 (3) 199 (1984).

12. G.F. Bocchini, Powder Metall., $\underline{30}$ (4) 261 (1987).

13. J. Cesarano, this volume.

14. S.J. Glass, this volume.

15. J.S. Reed, Principles of Ceramic Processing, Wiley and Sons, New York, 1988, pp. 336-345.

\section{DISCLAIMER}

This report was prepared as an account of work sponsored by an agency of the United States Government. Neither the United States Government nor any agency thereof, nor any of their employees, makes any warranty, express or implied, or assumes any legal liability or responsibility for the accuracy, completeness, or usefulness of any information, apparatus, product, or process disclosed, or represents that its use would not infringe privately owned rights. Reference herein to any specific commercial product, process, or service by trade name, trademark, manufacturer, or otherwise does not necessarily constitute or imply its endorsement, recom. mendation, or favoring by the United States Government or any agency thereof. The views and opinions of authors expressed herein do not necessarily state or reflect those of the United States Government or any agency thereof. 